\title{
Raça e gênero na construção de trajetórias de mulheres quilombolas
}

\author{
Maria Raquel Dias Sales Ferreira' (D) 0000-0002-2619-5497 \\ Carmem Lúcia Eiterer ${ }^{2}$ (D) 0000-0002-6978-155X \\ Shirley Aparecida de Miranda 2 (i) 0000-0001-8312-2262 \\ 'Colégio Santa Doroteia, Belo Horizonte, MG, Brasil. \\ 30315-520- https://www.fae.ufmg.br/ \\ ${ }^{2}$ Universidade Federal de Minas Gerais, Faculdade de Educação, Belo Horizonte, MG, \\ Brasil. 31270-901 - https://www.fae.ufmg.br/
}

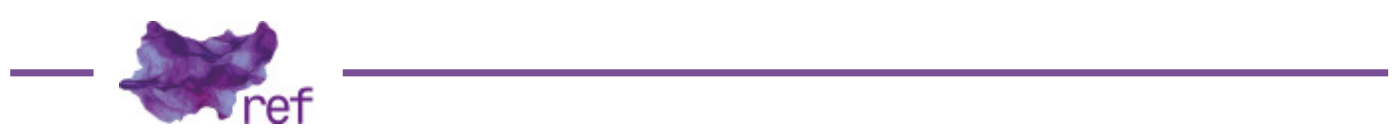

Resumo: No texto objetivamos analisar como um grupo de mulheres moradoras da Comunidade Quilombola Mato do Tição, situada na Região metropolitana de Belo Horizonte, mobiliza elementos para a construção do referente "mulher quilombola" na construção de suas identidades. Para tanto, a análise passa por reflexões em torno das práticas e dos discursos a partir dos quais essas mulheres tornaram-se quilombolas e das maneiras como mobilizam a categoria do gênero. O presente artigo partiu de uma etnografia, realizada por meio de observação participante, entrevistas e conversas direcionadas, cujo foco foi a trajetória de cinco mulheres da comunidade que protagonizam e mantêm - cotidiano do quilombo. Demonstramos que elas estão produzindo significados e deslocando os sentidos sobre sua própria identidade a fim de superarem as opressões sociais em torno do pertencimento étnico-racial e de gênero.

Palavras-chave: gênero; mulheres quilombolas; ancestralidade; relações de poder.

Race and Gender in The Course of Lives of Quilombolas Women

Abstract: This text aims to analyze how a group of women from the Quilombo Community Mato do Tição, located in the metropolitan area of Belo Horizonte, mobilizes elements for the construction of the referent "quilombola women" in the construction of their identities. For this purpose, the analysis goes through some reflections over the practices and discourses from where black women came to be quilombolas and how the category gender is linked to the category quilombola. This present work was based on an ethnography study of the five most active women in the quilombo carried out through observed participation, interviews and guided chats. It is shown that the group of women who had been studied as agents of their own culture are producing different meanings over their own ethnic and cultural identity and gender as well, in the public and private sphere by means of discourses based on tradition and ancestry.

Keywords: Gender; Quilombola Women; Ancestry; Relations of Power.

\section{Apresentação}

Neste artigo temos como objetivo analisar como um grupo de mulheres, moradoras da Comunidade Quilombola Mato do Tição, situada na Região metropolitana de Belo Horizonte, mobilizam dispositivos de raça e gênero para a elaboração do referente "mulher quilombola" na construção de suas identidades - pautada, muitas vezes, na opressão, na violência e no racismo. Entendemos gênero e raça como dispositivos de poder que se sustentam por meio de determinada prática discursiva, caracterizada pela fixação de normas para a elaboração de conceitos e teorias que "ganham corpo em conjuntos técnicos, instituições, esquemas de comportamento, em tipos de transmissão e de difusão, em formas pedagógicas, que ao mesmo tempo as impõem e 
mantêm" (Michel FOUCAULT, 1997, p. 11). A análise aqui proposta passa por reflexões em torno das práticas discursivas a partir das quais essas mulheres negras, de diferentes idades e gerações, mobilizam a categoria mulheres articulada à categoria quilombola.

Apresentamos aqui parte dos resultados de uma dissertação de mestrado, defendida em 2016, na Faculdade de Educação da UFMG, que teve como objetivo explicitar e analisar os modos de participação nas culturas do escrito de um grupo de mulheres pertencente à comunidade em questão. A rede de relações criada com as mulheres da comunidade nos possibilitou também o acesso a diversas informações a respeito da maneira como elas articulam e mobilizam suas identidades, de mulheres negras e quilombolas, na comunidade. Por isso, o trabalho trouxe outros desdobramentos que ultrapassam a relação delas com a cultura escrita, principalmente quando se considera que essa relação é política (Maria Raquel Dias Sales FERREIRA, 2016).

Durante o trabalho de campo, nos aproximamos da maioria das mulheres da comunidade, mas, principalmente, de algumas delas: Marilene, Dona Divina, Dona Nilse, Dona Bina e Rosaura. Utilizamos os nomes próprios e apelidos das pessoas da comunidade que aceitaram e autorizaram compor, conosco, a construção dessa narrativa.

Dentro dessa articulação - identidade/diferença - surgiu o questionamento: quais significados emergem quando o referente é "mulher quilombola"? No decorrer da pesquisa de campo, percebemos os deslocamentos de sentidos que são mobilizados pelas mulheres, em cada situação, para construir o referente em questão, normalmente com a intenção de se deslocarem da condição de subalternidade, de racismo e de opressão. No presente artigo temos como objetivo trazer essas reflexões.

\section{Percursos metodológicos}

A análise aqui presente partiu de uma pesquisa cuja metodologia foi qualitativa, que combinou narrativas biográficas, observação participante e entrevistas com os sujeitos. A escolha pela Comunidade Mato do Tição, evidentemente, não foi aleatória. Quando começamos a pesquisa exploratória, havíamos determinado algumas prioridades: ser uma comunidade próxima a Belo Horizonte - para facilitar e viabilizar idas e vindas no trabalho de campo -, entretanto, inserida em um contexto rural - fator que possibilita ainda especificidades no campo dos estudos em questão - e, principalmente, que (ainda) aceitasse pesquisadores em seus territórios. Além das entrevistas e conversas informais, a pesquisa foi feita a partir da observação participante, matériaprima da etnografia, como instrumento metodológico. No contexto da observação participante e nas imersões no campo, algumas mulheres se aproximaram e se abriram mais aos diálogos. Não por acaso, eram as mulheres que assumiam protagonismo e liderança na comunidade. Foram as narrativas dessas mulheres que ampararam e realização da escrita etnográfica.

\section{Quilombo}

Com o objetivo de ampliar a compreensão sobre as maneiras como o grupo de mulheres mobiliza elementos ligados à raça, à etnia e ao gênero para a elaboração do referente "mulher quilombola" na construção de suas identidades, é importante empreendermos aqui a apreensão do termo quilombo na dinâmica de uma prática discursiva. O termo "quilombo", ainda hoje, remete à ideia de homens e mulheres negros fugitivos da escravização. Essa concepção está relacionada à formulação do Conselho Ultramarino de 1740, que apresentou a definição quando o Rei de Portugal postulou que Quilombo seria: "[...] toda habitação de negros fugidos, que passem de cinco, em parte despovoada, ainda que não tenham ranchos levantados e nem se achem pilões nele". As origens de formação dos quilombos localizados no território brasileiro e dentro do território de Minas Gerais, entretanto, são diversas. Foram mediadas por processos variados, tais como fugas e ocupações de terras isoladas, doações de seus antigos donos, heranças, recebimento, compra, dentre outros, tanto durante a vigência da escravidão quanto após sua abolição, em 1888. Até chegarmos às atuais configurações políticas de um quilombo, houve muitos embates e discussões e o conceito adquire novos estatutos de acordo com o contexto em que está inserido.

O termo "quilombo", como categoria em disputa, é interpelado pelas teorias antropológicas que contribuem para o campo de ressemantizações e ressignificações do termo. Segundo Eliane Cantarino O'dwyer (2002), a categoria quilombo é um objeto simbólico que mobiliza interesses para os diversos sujeitos históricos a partir dos seus contextos. Já Clóvis Moura $(1981$; 1987) propõe o quilombo atrelado ao conceito de resistência, enfatizando-o como uma forma de organização política. Nessa mesma direção, o antropólogo Alfredo W. B. de Almeida (1998) ressalta a importância de que as terras quilombolas devam ser remetidas à organização territorial e à formalização jurídica das terras de uso comum.

A ressignificação do termo "quilombo" e dos sentidos que dizem respeito às Comunidades Remanescentes de Quilombos - termo oficial utilizado para referir-se às comunidades no contexto legal -, orienta as práticas discursivas do grupo em questão, já que a articulação da categoria 
quilombola passa também pelas formas como o Estado interage com a comunidade, reconhecendo-a ou não. Não se pode, portanto, fazer uma análise aprofundada sobre as formas como a identidade quilombola é mobilizada sem considerar como ela é vista e tratada no campo dos direitos constitucionais e das políticas públicas. Nossa trajetória, como interlocutoras da pesquisa, não está desarticulada da história dos quilombos.

A legislação federal atribui às comunidades quilombolas a posse definitiva de terra. 0 Estado assegura, conforme o artigo 68 que consta no Ato das Disposições Constitucionais Transitórias da Constituição Federal de 1988 - ADCT - (BRASIL, 1988), que "aos remanescentes das comunidades dos quilombos que estejam ocupando suas terras é reconhecida a propriedade definitiva, devendo o Estado emitir-Ihes os títulos específicos". Somente em 20 de novembro 2003, entretanto, o Decreto $n^{\circ} 4.887$ (BRASIL, 2003) regulamentou o artigo 68, estabeleceu os procedimentos e instrumentos pela demarcação e titulação das terras ocupadas por remanescentes das comunidades de quilombos. O documento prescreve os termos para a identificação, o reconhecimento, a delimitação, a marcação e a titulação de terras ocupadas. De acordo com os termos do Decreto (Art. $2^{\circ}$ ), quilombolas são "os grupos étnico-raciais, segundo critérios de autodefinição, com trajetória histórica própria, dotados de relações territoriais específicas, com presunção de ancestralidade negra relacionada com a resistência à opressão histórica sofrida". Esse Decreto define os atores políticos e os processos referentes à constituição das comunidades e exige a constituição de uma Associação Comunitária, uma entidade jurídica que represente os moradores das comunidades quilombolas.

Nesse sentido, segundo Ilka Boaventura Leite (2000), o quilombo, enquanto forma de organização, possibilita políticas e estratégias de reconhecimento a partir de três dimensões. A primeira, por meio da "responsabilidade do grupo em definir pleitos com legitimidade e poder de aglutinação, de exercer pressão e produzir visibilidade na arena política onde os outros grupos já se encontram" (LEITE, 2000, p. 345). A segunda, por intermédio do questionamento, indireto ou não, da função do estado, da utilização que fazem os políticos das bandeiras dos movimentos sociais. $\mathrm{E}$, em terceiro lugar, "propondo a revisão das prioridades sociais, através, principalmente, da implementação de políticas sociais voltadas para pleitos considerados mais importantes e representativos dos interesses destas comunidades" (p. 345).

A categoria quilombola não se refere, apenas, a uma identidade negra colada ao sujeito; parte de um patrimônio histórico aberto à exposição pública. O quilombo instaura uma ideia de coletividade, que, efetivamente, é responsável pelo deslocamento de uma condição de ausência de direitos até a garantia, mediada pelo poder político, de uma melhor existência, fazendo valer o conceito de cidadania (LEITE, 2000). Segundo a autora, "mais do que uma realidade inequívoca, o quilombo deveria ser pensado como um conceito que abarca uma experiência historicamente situada na formação social brasileira" (LEITE, 2000, p. 342).

Percebe-se, portanto, que a categoria e a questão atravessam os domínios discursivos do campo jurídico e das ciências sociais, considerado ora categoria analítica, ora categoria externa. O caminho adotado nesta investigação, entretanto, nos conduz a assumir o termo como categoria nativa, mobilizada pelas mulheres da Comunidade Quilombola do Mato do Tição, como forma de resistência e de garantia de direitos. Em 2006, a Comunidade Quilombola do Mato do Tição, representada pela Associação dos Moradores do Mato do Tição, recebeu o certificado da Fundação Cultural Palmares. A certificação suscitou mudanças nas maneiras como as moradoras e os moradores agenciam sua identidade enquanto comunidade negra, afrodescendente e quilombola, conforme analisaremos neste artigo.

\section{Mato do Tição}

Mato do Tição é uma comunidade que faz parte do conjunto de comunidades rurais no município de Jaboticatubas, localizado no vetor norte da região Metropolitana de Belo Horizonte. Atualmente, possui 35 núcleos familiares e aproximadamente 180 moradores, a maioria deles da família Siqueira. A fundação da comunidade está associada ao casal Benjamim e Josefa de Siqueira. Desde então, a comunidade viveu inúmeros conflitos, tensões e processos de expropriação envolvendo a luta pelo direito ao território e à existência. Apenas em 1981 conseguiram o direito ao usucapião, mantendo, até os dias atuais, os estreitos três hectares onde vivem.

Se, por um lado, a criação da associação possibilitou à comunidade ter um diálogo mais direto com o Estado e ter viabilidade na realização de projetos e na aquisição de recursos, por outro, começou a criar centralidades e, por vezes, tensões. Nesse contexto, como nos lembra Avatar Brah (2006), as categorias "eu" e "nós" não são unificadas e fixas, e, sim, contingentes, culturalmente construídas e se ressignificam de acordo com o contexto. Assim, histórias coletivas das mulheres quilombolas, marcadas pela experiência pessoal, inscrevem a biografia de cada uma. Brah (2006) nos diz:

'Histórias' coletivas são também, é claro, culturalmente construídas no processo de atribuir significado ao cotidiano das relações sociais. Mas, enquanto as biografias pessoais e histórias 
de grupo são mutuamente imanentes, elas são relacionalmente irredutíveis. O mesmo contexto pode produzir várias 'histórias' coletivas diferentes, diferenciando e ligando biografias através de especificidades contingentes (BRAH, 2006, p. 362).

A maioria das mulheres do Mato do Tição é "dona de casa". Elas cuidam das crianças, dos idosos e preparam a alimentação dos maridos. Algumas moças jovens ou adolescentes da comunidade cuidam de crianças, da própria comunidade ou de fora, algumas vezes de forma remunerada, outras vezes não. Há pessoas na própria comunidade que empregam mulheres também de lá para o trabalho doméstico. Algumas trabalham como empregadas domésticas diaristas, outras, em lojas e fábricas. Há algumas empregadas domésticas de sítios, casas, hotéis. Há, ainda, pessoas empregadas pela prefeitura de Jaboticatubas como Assistentes Comunitárias de Saúde. Muitas delas complementam a renda com a fabricação de artesanatos, como tapetes ou com a fabricação e venda de doces e salgados dentro da comunidade, ou fora, como nas feiras, ou nas próprias casas dos clientes.

A comunidade está situada a quatro quilômetros da sede do município de Jaboticatubas, para a qual a via de acesso é uma estrada de terra extremamente vulnerável às condições climáticas: a poeira em épocas de seca; os buracos e a lama em épocas de chuva. Do centro da capital até a comunidade, percorremos aproximadamente $65 \mathrm{~km}$. Não existe um ônibus municipal que liga a comunidade à sede. Nota-se, a partir desses indícios, a falta de políticas públicas municipais de mobilidade que visam à integração das comunidades do município, tendo em vista que as moradoras e os moradores de Mato do Tição dependem da sede de Jaboticatubas para trabalhar, fazer compras, ir à escola, aos correios e ter acesso aos serviços públicos de saúde.

Um dos espaços mais importantes para a comunidade é a Capela de Nossa Senhora de Lourdes, que é, na verdade, um pequeno cômodo multifuncional. Nesse espaço ocorrem as consultas médicas, as reuniões e as atividades da Associação. Na parte de trás, há um depósito onde são guardados instrumentos musicais, tambus, ' bonecos de desfile do carnaval, andores e ornamentos para festas. Ao lado, anexo ao prédio, fica o escritório da Associação Quilombola de Mato do Tição. É por meio dessa instituição que passam os diálogos com o Estado, a realização de projetos e a autorização de participação de pesquisadores e estudantes. Contudo, é importante ressaltar que nem sempre comunidade e associação são instâncias comuns: falar enquanto pessoas que representam a associação não significa falar enquanto comunidade. Marilene, muitas vezes, disse-nos de seu esforço em integrar a comunidade nas atividades da associação e também se queixou da falta de participação de muitas pessoas nas atividades, nas reuniões e nos projetos. Além desses conflitos, há inúmeros motivos de divisões e antagonismos - episódios de violência doméstica, desavenças em torno de projetos realizados, aparentes desigualdades na distribuição de recursos operam como divisores no tecido social da comunidade.

As primeiras moradoras da região do Matição foram as ex-escravizadas Ludovina Maria da Conceição e Rita Basílio. Benjamin de Siqueira era filho de Ludovina e de Marcolino, e Josefa era filha de João Francisco e Rita Baśílio. Mato do Tição tem origem do período pós-escravista, de acordo com Nubia Pereira Gomes e Edimilson de A. Pereira (1992, p. 300). A escravidão continua sendo uma marca indelével, reverberando um eco na vida das pessoas de Matição. Mesmo que se tornar quilombola seja negociar direitos a partir dessa categoria, as mazelas, as desigualdades, as injúrias são frutos de uma mentalidade escravocrata que, de certa forma, ainda persiste mesmo 131 anos após a abolição. Marcilene Silva (2011) mostra-nos que a condição de estigma vivenciada pelos moradores do Matição está relacionada com o passado escravista, diferentemente daquela vivenciada pelos demais negros integrados na cidade. Quilombola ainda é uma categoria vinculada à marginalidade, à criminalidade, à preguiça. Segundo a pesquisadora (2011), os moradores estão pouco presentes nos circuitos sociais de Jaboticatubas e praticamente ausentes no que tange ao diálogo com o poder público (p. 64).

A religiosidade é um elemento do Matiçẫo que desperta a atenção de muitos visitantes, jornalistas e estudantes. As festas, como o São João, cujo ritual mais conhecido é o de "passar nas brasas", assim como o Candombe, são elementos presentes em livros, reportagens e textos. A fé faz a comunidade ser comunidade e não está dissociada das demais práticas do dia a dia, como as festas, as rezas, a política e a luta por direitos. O Candombe é um ritual religioso que envolve cantos, aboio e dança e é praticado em muitas celebrações na comunidade: rezas, celebrações de santos, aniversário ou enterro de algum membro da comunidade, congregando homens, mulheres e diferentes gerações.

Podemos notar não só a participação intensa das mulheres, como a diversidade de atividades que elas exercem em torno do quilombo. No início do trabalho etnográfico, foi questionado à Marilene quais eram as lideranças da comunidade. Ela nos deu a seguinte resposta:

Difícil responder isso, porque, se você for ver, a D. Divina é a mais velha, nós todos temos muito respeito por ela, ela é a Matriarca da Comunidade, liderança religiosa, como se diz.

\footnotetext{
${ }^{1}$ Tambores sagrados utilizados no Candombe.
} 
D. Nilse é que resolve as coisas das festas, das rezas. Ela é... liderança da tradição, assim, né. Eu sou liderança também, eu que resolvo as coisas da associação, os projetos, os trabalhos, os documentos. Liderança política, como se diz. Mas todo mundo tem seu papel ali, cada pessoa faz sua parte (FERREIRA, 2016, p. 64).

\section{As interlocutoras}

As análises aqui presentes partiram da interação, em maior ou menor medida, das autoras com todas as pessoas da comunidade. Entretanto, as principais interlocutoras foram cinco: Marilene, D. Nilse, D. Bina, D. Divina e Rosaura, que serão apresentadas neste tópico, juntamente com suas trajetórias, em que articulam raça e gênero.

\section{Marilene}

Marilene foi nossa principal interlocutora. Ela se apresentou como liderança política, pois é responsável pelas funções burocráticas da comunidade e, em geral, é ela quem faz as mediações com o Estado. Presenciamos, durante o trabalho etnográfico, algumas de suas falas públicas. Para apresentá-la, é válido trazer fragmentos de uma dessas falas presentes em um festival de cultura quilombola. A mesa ${ }^{2}$ da qual participou tinha a seguinte temática: "Mulheres quilombolas na luta pelo bem viver". Ao narrar sua trajetória, ela diz que, quando começou suas atividades enquanto liderança política da comunidade, tinha muita dificuldade em situações de fala pública, mas, aos poucos, foi aprendendo as maneiras mais adequadas de colocar as ideias, o que se deve falar ou não em determinadas situações. Com o tempo e com a prática, a vergonha e a insegurança foram sendo substituída pela autonomia e, atualmente, tem facilidade com esse tipo de situação.

Quando ela narra a história da Associação Quilombola do Mato do Tição, é possível entender os deslocamentos de sentido em relação à raça e ao gênero. Para ela, seu primo Lindomar (Dó), que tomou frente no reconhecimento da comunidade, estava "ficando doido" e, quando ele a convidou para ser a vice-presidente, ela achou que "também teria que ficar doida". Diante de tanta burocracia, para Marilene, a questão quilombola parecia não fazer sentido. Enquanto aprendia a lidar com as especificidades burocráticas, aprendia também outros traquejos necessários para sua participação política e a relevância política daquele novo estatuto para a comunidade enquanto coletivo e para cada indivíduo que ali habitava:

À medida que eu fosse tendo dificuldade eu ia sendo obrigada a agir e a aprender. [...] E aí nós fundamos essa Associação, que eu passei a ser vice-presidente. Quando eu fui levando a documentação no cartório pra registrar, eu já sabia tudo de estatuto quilombola. Aí Dó fica falando: Ah, por que eu fundei a associação, não sei o quê. E eu falava: Peraí, Dó! Cê fundou não. Dá licença. Cê assinou! Porque quem resolveu a papelada toda foi eu!! E ele: Ah, mulher tem mais tempo pra essas coisas. Mulher tem mais tempo não! Quem te disse que eu tinha tempo? Eu deixava tudo na minha casa pra fazer isso. Passei a gostar daquilo. Me inteirar da causa e tal. Até porque era interesse da comunidade. [...] E assim foi nesse trabalho, porque quando venceu o mandato nós só invertemos os papéis, eu passei pro papel de presidência e ele passou pra ser vice. Ah, por que mulher no poder? [...] eu já sou liderança, ele é liderança, já tem mais lideranças. E hoje não é ele como presidente mais, não sou eu, já é uma outra mulher que é presidente (FERREIRA, 2016, p. 84).

Aqui, ela começa a articular sua trajetória política a uma maneira de se enunciar e de se posicionar enquanto mulher e liderança quilombola, que abre mão do cuidado no espaço privado para se dedicar às questões de interesse da comunidade. Ela continua seu depoimento, assinalando as articulações do feminino e do poder, destacando as relações desiguais, como o machismo, das quais ela necessita se deslocar para conquistar legitimidade, não só em momentos de falas públicas, como dentro da própria comunidade. Marilene segue em sua apresentação e, ao falar de sua comunidade, remete à Tia Tança, que, segundo os moradores da comunidade, é uma africana que deu origem ao quilombo. A remissão dessa figura demonstra a relação com a ancestralidade - conceito que orienta e dá veracidade à ideia do quilombo: ser quilombola, para ela, é ter vínculo com a ancestralidade:

Aí as pessoas casam, outras vão embora, sai da comunidade não vivem lá porque a gente não tem terra, não tem espaço. Mas o interessante é que cê pode ir pra onde você for, cê continua sendo quilombola. [...] Aquela pessoa coloca lá o endereço: Mato do Tição. Eu falo: Não é esse endereço não, mudou. Cê mudou??? Mudei não. Mudou foi o nosso endereço... Nós agora é Quilombo do Mato do Tição. Aí eles retrucam. Mas é a mesma coisa... lá no mesmo lugar. É a mesma coisa pra você que náo sabe o significado, pra mim representa muito. Ah, é? Então, me fala o que é quilombo? Eles acham que a gente tá achando que nós tão podendo, que nós tá muito chato. Aí aprendi com Tio Badu, né, tamo

\footnotetext{
${ }^{2}$ Mesa realizada na UFMG pelo projeto Canjerê - $1^{\circ}$ Festival de Cultura Quilombola de Minas Gerais, idealizado pela Federação Quilombola N'Golo.
} 
achando não, pois nós podemos. ${ }^{3}$ Nós temos história, sabemos de onde viemos, sabemos onde estamos e sabemos pra onde vamos. E você? Me diga a sua história? (FERREIRA, 2016, p. 85).

Neste trecho é possível perceber os deslocamentos de sentido em relação à raça, uma vez que a categoria "quilombola" passa a ser mobilizada com orgulho (não mais como algo atribuído à loucura), como uma forma de sair de uma condição de invisibilidade construída ativamente, tanto pela população, por meio de violência simbólica, quando pelo Estado, por meio da negligência e omissão de políticas públicas para garantia de direitos.

\section{Nilse}

Marilene se referiu à D. Nilse como uma "liderança da tradição". Ela é a filha mais nova do Benjamim e Josefa. É casada com Seu João e gosta de contar a história de quando se conheceram: Eu era namoradeira, tive 37 namorados e nunca gostei de homem branco. Escolhi o João no mercado: era o homem com o carrinho mais cheio. Com ele, teve 8 filhos, mas hoje apenas 6 estão vivos. Com a morte da filha Mônica, ficou responsável pela guarda de três netos. Atualmente, em sua casa, moram com ela Sr. João, seu filho Miro e os netos. Trabalhou como costureira e hoje está aposentada, mas também complementa a renda vendendo tempero caseiro, doces e artesanatos. D. Nilse estudou até o terceiro ano quando criança, mas voltou a estudar no MOVA (Projeto de Educação de Jovens e Adultos) recentemente. Ela sempre reitera o quanto as gerações que a sucedem avançaram socialmente. Essa constatação ela justifica:

Nós caminhou muito com ajuda de Deus que sempre nos ajudou muito, mas nós têm orgulho e pé no chão, e vamo lutando nessa ciranda. Eu tive que costurar presse Matição inteiro e até pro povo da rua pra criar meus filho, dar condição a eles a ter uma vida melhor que a nossa que nós irmãos teve (FERREIRA, 2016, p. 89).

Associada à luta individual como costureira para garantir o sustento de sua família, está também o entendimento e o manejo do que é ser quilombola. A agência da identidade quilombola se dá a partir do momento em que se entende que essa é uma maneira de proteger os direitos territoriais e étnicos, e não de perdê-los. Reeditar a categoria quilombola como algo que traz orgulho tem o mesmo fundamento que negar essa categoria: proteger-se dos processos de subalternidade. Em certa ocasião, D. Nilse me contou como foi, para ela, o processo de entendimento desse termo:

O povo falava que era quilombo, mas ninguém aceitava não! Ficou um tempão sem aceitar esse nome. [...] Porque nós velhos nós não aceitava porque, [...] nós achava que era pra piorar pra nós, aí ficava com medo, sabe? Já era descendência de escravo, e ainda ia aceitar o quilombo, nós tava achando que eles ia fazer a gente trabalhar mais do que já trabalhava, que nós ia passar pelo mesmo que a tia Tança passou, bem agora que tava começando a melhorar. Que absurdo, né? [...] Aí agora a gente fala com orgulho de ser quilombola. Então os mais velhos mesmo: Assina isso não, vai fazer nós de bobo! Eles vão fazer com nós igual eles fez, tomar as terra nossa, que custamo a conseguir. Aí ninguém aceitou esse nome. [...] porque ninguém queria ser sofrido, uai, porque se nós é sobrinho dela, ela passou por isso, e ainda vai registrar o quilombo... Mas hoje, graças a Deus, [...] nós é quilombola, nós tem orgulho do povo nosso (FERREIRA, 2016, p. 90).

\section{Divina}

D. Divina nasceu no dia 16 de setembro de 1930 e é a filha mais velha de Benjamim e Catita. Por causa disso, é conhecida como a "matriarca da comunidade". Além de Renato, D. Divina tem outros quatro filhos vivos: Marcolino, Duarte, René Júlio, Eurita. Desde muito nova, D. Divina trabalha com "cura"4 e, segundo ela, recebe gente de todo lugar. Atualmente, D. Divina é considerada liderança religiosa pelos membros do Matição e por pessoas de outras comunidades em Jaboticatubas. Mas foi também liderança política por muitos anos. A sua participação na vida pública e política era intensa. Segundo D. Divina, ela gostava de participar de todos os eventos festivos e políticos, independentemente de ir a pé, a cavalo ou de carona - o que, muitas vezes, suscitava ciúmes do marido.

\section{Bina}

Silvia de Siqueira tem o apelido de Bina desde a infância. Ela também é filha de Benjamin e Josefa, e é irmã gêmea de Silvio de Siqueira, Seu Badu. Foi à escola por um curto período. Sua infância foi marcada pela necessidade de muito trabalho. Trabalhava com a mãe e com o pai incessantemente na roça; trabalhava no moinho de farinha, na feitura da rapadura, capinando

${ }^{3}$ Em sua fala, Marilene deu muita ênfase a esse trecho.

${ }^{4} \mathrm{~A}$ forma como as pessoas da comunidade se referem à benzeção. 
roça. É viúva de Isaías (que também é seu "primo-irmão"), com quem teve quinze filhos, mas perdeu oito. Gosta de tocar gaita, pandeiro, caixa de folia, de dançar e de bater Candombe. É aposentada, mas faz artesanatos, faz sabão "dicuada" e tira óleo de mamona para complementar a renda. D. Bina sempre faz referência às dificuldades por que passou quando criança e para criar os filhos, muitas vezes passando fome; em dias de muita chuva, sem ter onde dormir. Acredita que, para as crianças, a coisa mais importante é o fato de elas poderem ir à escola, mas, segundo ela, "não podem deixar de participar dos festejos da comunidade".

\section{Rosaura}

Rosaura é casada com Marcolino, filho de D. Divina. Com ele tem três filhos. No momento da realização da pesquisa, ela trabalhava como empregada doméstica, por meio de vínculo informal, na casa de D. Nilse. Além de trabalhar todos os dias da semana na casa de D. Nilse, também faz pastéis para vender tanto em eventos da cidade quanto em eventos, festas e rezas da própria comunidade. Rosaura não teve oportunidade de frequentar a escola quando criança. Ela sempre está na cozinha envolvida com o preparo dos alimentos em dias de festa ou de reza. Mas seu espaço em Matição é delimitado por ser sempre alguém que veio "de fora". Diversas vezes, essa "não autorização" passa por sua não ligação com a ancestralidade, dessa forma, com a tradição, cujo compromisso é dos seus filhos. Se a ancestralidade é o elemento que qualifica e dá sentido ao referente "mulher quilombola", Rosaura passa a ser apenas uma mulher negra que mora em Matição, e não alguém do Matição. É esse o lugar de fala que ela assume. Ela nos mostra que as articulações de gênero estão além da oposição entre masculino e feminino (na qual há uma relação de poder que envolve, por exemplo, violência doméstica). O gênero é articulado também entre outras relações de poder que são internas às relações entre as mulheres. A diferença é articulada dentro do gênero, "portanto, é uma questão contextualmente contingente saber se a diferença resulta em desigualdade, exploração e opressão ou em igualitarismo, diversidade e formas democráticas de agência política" (BRAH, 2006, p. 374).

Rosaura tem em comum com as outras mulheres da comunidade o fato de ser uma mulher negra. Ela participa dos eventos da comunidade, é mãe de jovens que têm a herança da ancestralidade da comunidade, cuida, limpa, cozinha e participa e é, inclusive, reconhecida por tudo que faz na comunidade. Entretanto, a sua fala marca um pertencimento do qual ela não faz parte. Ela não é uma voz que legitima a experiência quilombola na comunidade, ainda que, em determinados momentos, ela acione um "nós"; em outros, ela acione um "eles", demonstrando a contingência da identidade marcada pela experiência. As relações de poder, que são parte da heterogeneidade de pessoas de um grupo "identitário", não desaparecem, ao contrário, emergem, ao se deslocar o lugar de fala e criar situações que definem ou não o pertencimento. Isso só aponta para o fato de que a identidade quilombola é uma prática discursiva contingente, e não essencialista, como pontuou Brah (2006). Rosaura ingressa no Matição, mas não pode pertencer ao quilombo. Dessa forma, os limites da comunidade quilombola não são definidos, são fronteiras fluidas, pois admitem entradas, mas que se reeditam de acordo com o contexto.

\section{Identidade e ancestralidade}

Para o povo do Matição, os "ancestrais são os parentes que já morreram". As mulheres remetem, em seus discursos, aos ancestrais, como uma maneira de resistência ao justificarem as atividades que são essenciais na formação e na manutenção da comunidade: as rezas, as festas, os encontros, as formas de se fazer artesanato, as curas e as habilidades na cozinha. A ancestralidade, dessa forma, não é apenas um elemento que organiza as experiências na comunidade, é também um recurso discursivo engajado em uma luta social, fornecendo as bases emocionais, políticas e legítimas para as ações de luta pelos direitos. Ao considerarmos as condições históricas a que foram sujeitadas as mulheres da comunidade, podemos conceber que a diferença étnico-racial, pautada pela ancestralidade, é um elemento político. Ou seja, as marcas da "diferença", como as rezas, as danças, os rituais e a culinária estão articuladas ao direito ao território e à identidade, responsáveis pelo deslocamento da condição subalterna.

Uma das referências para as mulheres da comunidade é Tia Tança, que já foi citada anteriormente. Ela nasceu em 1828 e morreu aos 135 anos. Segundo as moradoras do quilombo, Tia Tança foi uma das responsáveis pela fundação e pela formação da comunidade. Ao se referirem a ela, evocam uma mulher muito forte, que ajudou a criar os filhos de Benjamim e de Josefa, uma mulher trabalhadora e dedicada, que foi responsável por transferir muitos dos ensinamentos até hoje utilizados na comunidade, como nossas interlocutoras dizem. Com ela, elas aprenderam muitos ofícios e até uma língua ligada aos povos africanos. Ela é lembrada pelas vestes africanas, pelas habilidades no Candombe e por ser devota de Nossa Senhora do Rosário. No processo de negociação com as novas "africanidades", Tia Tança começou a ser um elemento-chave que, de alguma maneira, traz veracidade e legitimidade ao quilombo. Benjamim 
e, com menos frequência, Josefa, também são ancestrais fundadores evocados em eventos importantes para o quilombo, como a devoção aos santos, a Folia de Reis e o Mês de Maria.

A ancestralidade, ao compor a prática discursiva do quilombo, está, portanto, imbricada nas relações de poder e nas maneiras de mobilizar, negociar, aceitar ou negar a identidade, fundamentada na diferença, em constante agência. As mulheres mais velhas - filhas do casal Benjamim de Siqueira e Josefa -, D. Nilse, D. Divina e D. Bina sempre reafirmam que elas são "da mistura de índio com africano", como gostam de dizer. Segundo elas, as pessoas da comunidade fazem práticas indígenas, como a utilização de raízes e ervas nas curas, e práticas africanas, como o Candombe. A parte indígena é do pai, Benjamin de Siqueira: "ninguém mandava nele não, era dos índio, né, e ninguém manda nos índio". "Ele foi um guerreiro aqui ajudando o povo dessa terra aqui tudo", ou "Papai era raizero, aí eu acompanhava ele nesses mato buscando remédio, que ele aprendeu com os povo dele, e eu aprendi com ele", ainda, "Papai ele era dos índio, né, aí ele sabia muito das coisa no mato, dos remédio, aí eu faço os remédio até hoje, é ruim eu sair daqui pra ir no médico" - são algumas das frases atribuídas à herança indígena.

A mãe, Josefa Baślio dos Santos: "minha mãe, coitada, africana, descendente dos escravos". "Minha mãe, a Catita, ela fazia de tudo, [...] o povo vinha era de longe atrás das coisa da Catita, e ela fazia pra todo mundo, gostava de agradar todo mundo, trabalhava dia e noite, é por isso que a Tança ajudou a criar nóis". "Meu pai ensinou ela a escrever pelo menos o nome, mas coitada, era analfabeta de tudo, africana, né." São algumas das falas que permearam a etnografia sobre a herança africana. É interessante destacar aqui essa conjugação da ancestralidade da Comunidade Quilombola do Mato do Tição de negros africanos e indígenas. Quando ela é mobilizada, cria-se um efeito de distanciamento da imagem do quilombo como algo criminalizável, marcado pelo estigma da escravidão. É por isso que trazer a parte de tradição indígena do pai está atrelada a uma resistência que foge da opressão sofrida pelo povo negro. É uma maneira de dar contornos ao racismo e ao legado da escravidão que traz consequências tão graves na comunidade.

Os relatos das mulheres remetem, frequentemente, à ancestralidade ligada à tradição. Falam de "pegar compromisso", de "honrar os antigos". A fala de D. Nilse a respeito das rezas ilustra esse comprometimento: "das três coisas mais antigas que têm é a Folia de Reis, o mês de Maria e o São João. A Folia de Reis tem mais de 400 anos. E vai passando de geração em geração". Assim, a relação com a ancestralidade é um meio com o qual e pelo qual se produzem e atualizam os significados e se operam os sentidos do que é ser quilombola. Por serem elas portadoras da voz que carrega e mantém viva a memória ressignificada e a voz dos ancestrais, são, portanto, guardiãs de saberes e produtoras de práticas discursivas que constituem, produzem e atualizam a Comunidade Quilombola do Mato do Tição.

\section{Mulheres negras, mulheres quilombolas}

O termo "mulheres quilombolas" sugere uma identidade institucionalizada, pronta. Entretanto, as interlocutoras da pesquisa trazem diferentes experiências, diferentes vivências - assim, diferentes significações - no tocante à construção da própria identidade e da identidade coletiva. A comunidade abrigava quatro gerações, o que possibilita a experiência de conflitos distintos e de inúmeras representações do que é ser quilombola.

No decorrer da pesquisa de campo nos deparamos com situações nas quais o referente 'mulher quilombola' significava, dentre outras possibilidades, força e resistência - signo da ancestralidade, e diante de outras, em que a expressão trazia a ideia de opressão e sofrimento. As primeiras ocorreram mais comumente em ambientes marcados por uma forte presença institucional - como reuniões em secretarias ou prefeituras, visitas de escolas na comunidade etc. Assim, há momentos nos quais os discursos em que elas manejam o referente 'mulher quilombola' aparecem articulados em espaços políticos. Em outros momentos, esses discursos são atravessados e definidos pelo contexto privado, marcado pelas conversas em casa, na cozinha, atravessados pelas memórias ligadas ao processo do casamento e do cuidado com os filhos.

O contexto das interlocutoras está ligado às condições históricas marcadas pelo racismo, pelo sexismo e pela exclusão social. Mulher quilombola, assim, parte da diferença e opera como um "sinal contingente em diferentes circunstâncias políticas", conforme Homi Bhabha (2007, p. 332). Nessa direção, é interessante também trazer o ponto de vista de Bhabha (2007) a respeito da diferença étnica que, para ele, nunca pode ser trabalhada como uma identidade dada a priori. É, antes, a produção de uma imagem e as maneiras como os sujeitos interagem com essa imagem, negando, afirmando ou negociando. Esse aspecto se torna ainda mais visível ao tratarmos a produção do quilombo como uma prática discursiva, que, no decorrer da história, ora é negado (como forma de se protegerem dos estigmas sociais ligados ao racismo e ao legado da escravidão), ora é acionado (também como forma de se protegerem desses estigmas sociais e de lutarem pela garantia de direitos territoriais e identitários). 
Nessa direção, de acordo com Stuart Hall (2005, p. 13), a cultura e a identidade são definidas histórica e politicamente e não estão unificadas ao redor de um "eu" coerente. As identidades são contraditórias e tencionam para diferentes direções e deslocamentos. Nas palavras de Hall (2000, p. 80), "se sentimos que temos uma identidade unificada desde o nascimento até a morte é apenas porque construímos uma cômoda estória sobre nós mesmos ou uma confortadora 'narrativa do eu'”. A cultura, para Hall (2013), é vista ainda como a interpelação de padrões, de vivências e de experiências em um contexto específico.

A luz lançada pela experiência da diáspora, presente nas narrativas, marca as constantes ressignificações simbólicas com as culturas africanas (HALL, 2013). O autor levanta algumas questões importantes a serem pensadas nos diversos contextos diaspóricos:

Como podemos conceber ou imaginar a identidade, a diferença e o pertencimento após a diáspora? Já que a 'identidade cultural' carrega consigo tantos traços de unidade essencial, unicidade primordial, invisibilidade e mesmice, como devemos "pensar" as identidades inscritas nas relações de poder, construídas pela diferença, e disjuntura? (HALL, 2013, p. 30).

Hall, com o intuito de elaborar respostas a esses questionamentos, traz a seguinte reflexão que também nos cabe no contexto quilombola:

O conceito fechado de diáspora [...] está fundado sobre a construção de uma fronteira de
exclusão e depende da construção de um 'Outro' e de uma oposição rígida entre o dentro e
o fora. Porém, as configurações sincretizadas da identidade cultural caribenha requerem a
noção derridiana de différance - uma diferença que não funciona através de binarismos,
fronteiras veladas que não separam finalmente, mas são também places de passage, e
significados que são posicionais e relacionais, sempre em deslize ao longo de um espectro sem
começo nem fim (HALL, 2013 , p. 36 ).

As interlocutoras da pesquisa são o resultado de sua formação relativamente autônoma, na luta pela existência e pela sobrevivência. Essa (re)existência implica negociar uma nova africanidade. Produz-se uma cultura e trabalha-se nela. Assim, a cultura não é apenas uma viagem de retorno às origens ou de redescoberta. Segundo Hall, a cultura não é uma arqueologia, e sim uma produção. Em suas palavras: "não é uma questão do que as tradições fazem de nós, mas daquilo que nós fazemos de nossas tradições" (HALL, 2013, p. 49).

Nessa discussão, é valido problematizar - na mesma direção de Hall -, como pontuou Avtar Brah (2006), a ideia de "essencialismo", recorrentemente associada a termos relativos à identidade e à cultura. As experiências sociais particulares não devem, segundo a autora, ser interpretadas enquanto "essência" ou categorias fixas, mas, sim, como "historicamente contingentes de contestação de práticas discursivas e materiais" (p. 331).

Os moradores do Mato do Tição, com as vivências e as experiências dessa trajetória e conquistas políticas, ressignificam a sua identidade quilombola e passaram a reivindicar os seus direitos a partir dessa nova categoria. Se, por um lado, ao estabelecermos fronteiras categóricas, corremos o risco do essencialismo, conforme apontou Brah (2006); por outro, ao ignorar a diferença, particularmente ao tratarmos de grupos subalternizados, como os quilombolas, corremos o risco de se dissiparem as relações de poder, impossibilitando assim ou impedindo a implementação de políticas públicas específicas, como a própria questão de demarcação de terras para comunidades quilombolas, que são essenciais para a garantia de direitos e para a emergência dos sujeitos.

Ainda seria apropriado trazer a perspectiva de Hall (2013), que propõe uma concepção mais ampla do racismo, "que conheça a forma pela qual, em sua estrutura discursiva, o racismo biológico e a discriminação cultural são articulados e combinados" (HALL, 2013, p. 69). Nas desigualdades sociais que marcam a realidade de grupos tratados com "étnicos" ou "raciais", operam-se duas lógicas do mesmo racismo, apesar de sofrerem "combinações diferentes e sejam[serem] priorizadas distintamente, de acordo com o contexto ou a relação a diferentes populações subjugadas" (HALL, 2013, p. 69). Nesse sentido, convém recorrer novamente a Brah (2006). A autora defende o fato de que, muitas vezes, o termo "negro" serve para ocultar necessidades culturais de diferentes grupos, já que se baseia, muitas vezes, no "etnicismo". Segundo ela, esse termo define a experiência de grupos racializados em aspectos culturais e postula a diferença étnica como modalidade principal, independentes de outras experiências sociais em torno de gênero, classe, raça ou sexualidade, impondo "noções estereotipadas de 'necessidade cultural comum' sobre grupos heterogêneos com aspirações e interesses sociais diversos". Além disso, o poder público "frequentemente deixa de tratar da relação entre a 'diferença' e as relações sociais de poder em que ela pode estar inscrita. É evidente que é importante que o Estado seja sensível à pluralidade de necessidades entre seus cidadãos" (BRAH, 2006, p. 337).

Diante da racialização de um corpo, muitas vezes considerado selvagem e primitivo, conforme Margareth Rago (2008), "símbolo quintessencial de uma presença feminina natural, orgânica, mais próxima da natureza, animalística e primitiva", segundo bell hooks (1995, p. 468), as mulheres 
negras vivem, cotidianamente, efeitos de extrema violência, que associam racismo ao sexismo, trazendo novas marcas para suas trajetórias. Joan Scott (1995), ao conceber a ideia de que o gênero é uma categoria de análise, propõe um questionamento sobre como ele dá um sentido à organização, à percepção do conhecimento histórico. Entender o gênero, então, para a autora, pressupõe analisar não só as relações das experiências masculinas e femininas, mas também pressupõe analisar as práticas históricas dessas relações. Já segundo Sueli Carneiro (2003),

ao politizar as desigualdades de gênero, o feminismo transforma as mulheres em novos sujeitos políticos. Essa condição faz com esses sujeitos assumam, a partir do lugar em que estão inseridos, diversos olhares que desencadeiam processos particulares subjacentes na luta de cada grupo particular. Ou seja, grupos de mulheres indígenas e grupos de mulheres negras, por exemplo, possuem demandas específicas que, essencialmente, não podem ser tratadas, exclusivamente, sob a rubrica da questão de gênero se esta não levar em conta as especificidades que definem o ser mulher neste e naquele caso (CARNEIRO, 2003, p. 119).

Ainda segundo Carneiro (2011), faz-se necessário pensar o gênero como uma categoria articulada a outras formas de opressão, e não de forma desarticulada delas, principalmente quando se trata de sociedades multirraciais, pluriculturais e racistas, que impactam, diretamente, as relações de gênero. Angela Davis (2016), nessa mesma direção, demarca uma importante articulação em relação aos eixos de opressão. Para a autora, a escravidão, uma das maiores formas, segundo a autora, de violência ocorrida no planeta, não teve um fim logo após a abolição, uma vez que deixou importantes legados, sobretudo para as mulheres negras (por exemplo, a associação delas quase constante com o trabalho doméstico).

Por isso, a experiência de mulheres negras que vivem em uma comunidade quilombola rural, sob as marcas da escravidão, agrega ainda outras especificidades e outras rupturas em suas trajetórias. Segundo Brah (2006, p. 341), "vidas reais são forjadas a partir de articulações complexas" e é essencial que o signo mulher não seja uma categoria unitária. Temos, então, discursos de diferentes feminilidades, que partem de diferentes formas de feminino, simbolizam circunstâncias materiais e experiências culturais históricas particulares, assinalando para a perspectiva da diferença: de condições sociais e de processos estruturais ideológicos. As mulheres, dessa forma, são tomadas como sujeitos que emergem como efeitos de construções discursivas, a partir de suas trajetórias e de suas experiências culturais (RAGO, 2008).

Essas questões apontam para a necessidade de uma análise mais aprofundada sobre a diferença - e não mais sobre a identidade - como categoria analítica. Esse conceito, conforme pontuou Brah (2006), refere-se às variedades de formas como os discursos a respeito da diferença são mobilizados, ora podendo resultar em práticas de desigualdade e exploração, ora como forma de agência política. Segundo a autora, há construções de diferenças que postulam fronteiras fixas e imutáveis entre grupos tidos como inerentemente diferentes. Exemplo dessas fronteiras, o racismo. Há ainda outras construções que apontam a diferença como "relacional, contingente e variável", não sendo um marcador de hierarquia e opressão. Assim, ela conclui que é "uma questão contextualmente contingente saber se a diferença resulta em desigualdade, exploração e opressão ou em igualitarismo, diversidade e formas democráticas de agência política" (BRAH, 2006, p. 374).

Para continuidade à reflexão, Brah conceitua a diferença a partir de três esferas: diferença como experiência, diferença como relação social, diferença como subjetividade e diferença como identidade (BRAH, 2006, p. 359). No contexto do Mato do Tição, a diferença permeia essas três dinâmicas, o que varia de acordo com o contexto e com os atores envolvidos. A noção de diferença como experiência não se trata apenas de uma linha que delimita uma fronteira, por exemplo, entre os "quilombolas do Matição" e os "de fora", mas se configura também como encontros dentro das fronteiras. Para a autora, a experiência é uma construção cultural, um lugar de formação do sujeito e não reflete uma realidade pré-determinada, um processo de significação que é a condição para a constituição da realidade. Experiência é, portanto, a prática de produzir sentido "tanto simbólica como narrativamente: como uma luta sobre condições materiais e significado" (BRAH, 2006, p. 360).

Já a diferença como identidade é colocada pela autora ao conceber as identidades como intimamente ligadas à experiência, à subjetividade e às relações sociais, já que elas são "inscritas através de experiências culturalmente construídas em relações sociais" e "marcadas pela multiplicidade de posições de sujeito que constituem o sujeito", assumindo "padrões específicos diante de conjuntos particulares de circunstâncias pessoais, sociais e históricas" (BRAH, 2006, p. 371). Além disso, as identidades sempre se articulam com a experiência coletiva de um grupo, mas carregam especificidades "esboçadas nas minúcias diárias" que não se espelham na experiência do grupo, da mesma maneira que as identidades coletivas não são redutíveis à soma das experiências individuais.

Dessa forma, a proclamação de uma identidade coletiva é política e envolve a criação dessa identidade a partir de colagens de subjetividades e de experiências. Isso quer dizer que "a 
mobilização política diz respeito centralmente a tentativas de re-inscrever a subjetividade através de apelos à experiência coletiva". Entretanto, "a comunalidade que é evocada pode ser tornada significativa apenas em articulação com um discurso de diferença" (BRAH, 2006, p. 352).

\section{Conclusão}

As mulheres da Comunidade Quilombola do Mato do Tição reinstauram o mito de origem da comunidade em torno do processo de escravidão em continuidade do racismo. Por meio das narrativas de suas trajetórias, nas quais há vários episódios que demonstram como a ausência de direitos, as dificuldades de acesso à saúde, educação, ao trabalho e à terra - elementos que demarcam uma fronteira entre "os de fora" e "os do Matição" -, é possível perceber a perspectiva que elas têm da comunidade: se perceberem enquanto não pertencentes à sociedade. Nesse contexto, a questão quilombola opera em duas esferas: a princípio, negam-se a uma identificação que possa fazer com que eles retrocedam nos direitos que já haviam conquistado. Os deslocamentos de sentido se dão ao negarem que se trata de um quilombo por terem medo ao retrocesso da escravidão, e entenderem e se afirmarem enquanto quilombo como algo para impedir esse retrocesso.

Essa dinâmica de aceitação e de atualização da identidade negra e quilombola, de ora negá-la, ora acioná-la, é uma negociação, um caminho encontrado para sair de uma situação de subalternidade a que estavam submetidos há muitas gerações. Nesse sentido, passam a falar com orgulho dos avanços sociais e políticos, além das próprias manifestações culturais, como o Candombe, as rezas, as festas, já que entenderam que essas manifestações também são uma forma de operar com a diferença para lutar pelos direitos. A partir dessa ressignificação, a diferença que demarca a fronteira entre os quilombolas e os "de fora" passa a ser artefato político. Ser quilombola, para elas, portanto, não é uma base na qual se constrói uma identidade. É, antes, uma base com a qual se ressignificam as identidades em jogo no tecido das relações. Quilombola nomeia agenciamentos territoriais, políticos, jurídicos, burocráticos, culturais, semióticos e sociais.

Os agenciamentos das categorias identitárias das mulheres em prol da resistência inspiram as maneiras de lidarem com um mundo que, muitas vezes, as desaloja de sua humanidade. Na produção das relações sociais e das subjetividades, por meio dos discursos, elas combatem as sínteses hierárquicas, engajam-se politicamente, atravessam o meio burocrático do Estado, renovam os pressupostos e persistem, possibilitando a narrativa de uma existência e de uma história.

Ao final desse artigo, lembramo-nos da indagação de Marilene sobre a devolução do trabalho de pesquisa à comunidade e de sua decisão de ter seu nome verdadeiro no trabalho, por ser essa uma maneira, também, de dar visibilidade às pessoas da comunidade. É isso, então, que esperamos com a publicação deste artigo: possibilitar a mais pessoas que conheçam, ainda que por meio de um pequeno recorte acadêmico, um pouco da história dessas mulheres, que, ao tecerem suas histórias, tecem uma história de resistência e de existência de um quilombo.

\section{Referências}

ALMEIDA, Alfredo. "Os quilombos e as novas etnias: é necessário que nos libertemos de definições arqueológicas". In: REUNIÃO DA ASSOCIAÇÃO BRASILEIRA DE ANTROPOLOGIA, 21, Anais... 1998, Vitória. Mimeo.

BHABHA, Homi K. O local da cultura. Belo Horizonte: EDUFMG, 2007.

BRAH, Avtar. "Diferença, diversidade, diferenciação". Cadernos Pagu, Campinas, v. 26, p. 329376, jun. 2006.

BRASIL. Constituição (1988). Constituição da República Federativa do Brasil. Brasília, DF: Senado; Horizonte Ltda., 1998.

BRASIL. Ministério da Cultura. Decreto $n^{\circ}$ 4.887. Diário Oficial da República Federativa do Brasil. Brasília: Senado Federal, 2003.

CARNEIRO, Sueli. “Mulheres em movimento”. Estudos Avançados, São Paulo, v. 17, n. 49, p. 11 1-132, set./dez. 2003.

DAVIS, Angela. Mulheres, raça e classe. São Paulo: Boitempo, 2016.

FERREIRA, Maria Raquel Dias Sales. Mulheres quilombolas e culturas do escrito: voz e letra na comunidade quilombola do Mato do Tição/MG. 2016. Dissertação (Mestrado) - Programa de PósGraduação em Educação, Conhecimento e Inclusão Social, Faculdade de Educação, Universidade Federal de Minas Gerais, Belo Horizonte, Brasil. 
FOUCAULT, Michel. Resumo dos cursos do collège de France (1970-1982). Rio de Janeiro: Jorge Zahar, 1997.

GOMES, Nubia Pereira; PEREIRA, Edimilson de A. Mundo encaixado; significação da cultura popular. Belo Horizonte: Mazza, 1992.

HALL, Stuart. A identidade cultural na pós-modernidade. Rio de Janeiro: DP\&A, 2005.

HALL, Stuart. Da diáspora: identidades e mediações culturais. Belo Horizonte: EDUFMG, 2013.

HALL, Stuart. "Quem precisa da identidade?". In: SILVA, Tomaz Tadeu da (Org.). Identidade e Diferença. Petrópolis: Vozes, 2000. p. 103-133.

hooks, bell. "Intelectuais Negras". Revista Estudos Feministas, Florianópolis, v. 3, n. 2, p. 464-478, jan. 1995.

LEITE, Ilka Boaventura. "Os quilombos no Brasil: questões conceituais e normativas". Etnográfica, Florianópolis, v. 4, n. 2, p. 333-354, 2000.

MOURA, Clóvis. Rebeliões na Senzala, Quilombos, Insurreições, Guerrilhas. São Paulo: Ciências Humanas, 1981.

MOURA, Clóvis. Quilombos, Resistência ao Escravismo. São Paulo: Ática, 1987.

O'DWYER, Eliane Cantarino. Quilombos: Identidade étnica e territorialidade. Rio de Janeiro: FGV, 2002.

RAGO, Margareth. "O corpo exótico, espetáculo da diferença". Revista Eletrônica Labrys, jan./jun. 2008. Disponível em https://www.labrys.net.br/labrys13/perspectivas/marga.htm. ISSN:1676-1951. Acesso em 25/06/2014.

SILVA, Marcilene da. Conflito, estigma e resistência: um estudo a partir da comunidade quilombola do Matição - MG. 2011. Tese (Doutorado em Educação) - Faculdade de Educação da Universidade de São Paulo, Universidade de São Paulo, São Paulo, 2011.

SCOTT, Joan. "Gênero: uma categoria útil de análise histórica". Educação e Realidade, Porto Alegre, v. 1, n 1, p. 71-100, fev. 1995.

Maria Raquel Dias Sales Ferreira (mqueld@prof.dorotheus.com.br) é graduada em Letras. Professora. Mestre em Educação pela UFMG.

Carmem Lúcia Eiterer (carmenl@ufmg.br) é graduada em Filosofia pela FFLCH-USP. Mestre e doutora em Educação pela Faculdade de Educação - USP. Professora Associada da Faculdade de Educação - UFMG. Integra o Programa de Pós-Graduação da mesma instituição. Pesquisadora do NEJA-UFMG.

Shirley Aparecida de Miranda (smiranda@ufmg.br) é graduada em Filosofia pela PUC Minas, mestre e doutora em Educação pela Faculdade de Educação - UFMG. Integra o Programa Ações Afirmativas da UFMG e o Programa de Pós-Graduação da mesma instituição. 


\section{COMO CITAR ESSE ARTIGO DE ACORDO COM AS NORMAS DA REVISTA}

FERREIRA, Maria Raquel Dias Sales; EITERER, Carmem Lúcia; MIRANDA, Shirley Aparecida de. "Raça e gênero na construção de trajetórias de mulheres quilombolas". Revista Estudos Feministas, Florianópolis, v. 28, n. 3, e $63121,2020$.

\section{CONTRIBUIÇÃO DE AUTORIA}

Maria Raquel Dias Sales Ferreira: concepção, coleta de dados e análise de dados, elaboração do manuscrito, redação, discussão de resultados.

Carmem Lucia Eiterer: concepção, análise de dados, elaboração do manuscrito, discussão de resultados.

Shirley Aparecida de Miranda: concepção, análise de dados, elaboração do manuscrito, discussão de resultados.

\section{FINANCIAMENTO}

O presente trabalho foi realizado com apoio da Coordenação de Aperfeiçoamento de Pessoal de Nível Superior - Brasil (CAPES) - Código de Financiamento 001.

\section{CONSENTIMENTO DE USO DE IMAGEM}

Não se aplica.

\section{APROVAÇÃO DE COMITÊ DE ÉTICA EM PESQUISA}

CAAE 38734114.0 .0000 .5149

\section{CONFLITO DE INTERESSES}

Não se aplica.

\section{LICENÇA DE USO}

Este artigo está licenciado sob a Licença Creative Commons CC-BY International. Com essa licença você pode compartilhar, adaptar, criar para qualquer fim, desde que atribua a autoria da obra.

\section{HISTÓRICO}

Recebido em 12/04/2019

Reapresentado em 04/12/2019

Aprovado em 07/02/2020 